$(1,2,2,2)$ tetrahydrooctyltrichlorosilane was then deposited as an anti-sticking agent. Gold dots, which are the catalyst to control the later nanowire (InP) growth, were then patterned by metal evaporation and lift-off. The nanowire was formed in a metalorganic vapor-phase epitaxy system by a vapor-liquid-solid growth technique. Scanning electron microscopy showed that the nanowires were $\sim 1.5 \mu \mathrm{m}$ long with a diameter of $\sim 290 \mathrm{~nm}$.
By combining the nanoimprinting and self-assembly of nanostructures, this technique may be used to design nanowires by controlling the size of the catalyzing gold particles, which determines the diameter of the wires, said the researchers. It can also govern the length of the wire by the control of the growth time. The researchers said that this technique would provide a method for fabricating monolithic nanoimprint lithographic stamps and expanding the application areas of nanowires as well.

LuCY Yue Hu
FOR MORE RESEARCH NEWS ON MATERIALS SCLENCE . . access the Materials Research Society Web site:
www.mrs.org/gateway/matl_news.html

\title{
News of MRS Members/Materials Researchers
}

Aldo R. Boccaccini, of Imperial College London, received the Materials Science and Technology Prize 2003 from the Federation of European Materials Societies (FEMS) for "his contribution as a most promising and talented young materials scientist."

Greg Boebinger, of Los Alamos National Laboratory, has been named director of the National High Magnetic Field Laboratory (NHMFL). Boebinger previously served as the director of the pulsed magnet facility at Los Alamos; he succeeds Jack Crow, who was director of the NHMFL since its founding in 1990.

Theodorian Borca-Tasciuc, director of the Nanoscale Thermophysics and Energy Conversion Laboratory (NanoTEC) and assistant professor of mechanical, aerospace, and nuclear engineering at Rensselaer Polytechnic Institute has been awarded a Faculty Early Career Development Award (CAREER) from the National Science Foundation.

Scott Chambers, of the U.S. Department of Energy's Pacific Northwest National Laboratory, has been selected as the 2004 recipient of the E.W. Mueller Award from the University of Wisconsin for outstanding research in surface science. He is being recognized for advancing the science of molecular-beam epitaxy and applying it to fundamental investigations of the structural, electronic, and magnetic properties of metal oxide films, surfaces, and interfaces.

C.J. Ellison and J.M. Torkelson, of Northwestern University have received the 2004 Wiley Journal of Polymer Science (Part B) Prize for their article, "Sensing the Glass Transition in Thin and Ultrathin Polymer Films via Fluorescence Probes and Labels," published in the December 15, 2002, issue of the Journal of Polymer Science, Part B: Polymer Physics 40 (24) p. 2745. The award honors the best paper published in the journal during the previous two years.

Diana Farkas professor of materials science and engineering in the College of Engineering at Virginia Tech, received the university's 2003 Alumni Award for Excellence in Research.

Terence Langdon of the University of Southern California (USC) has been named the William E. Leonhard Professor of Engineering at USC. He was also elected a fellow of the Royal Academy of Engineering (U.K.) and awarded the degree of doctor honoris causa by the Russian Academy of Sciences.

Jyotirmoy Mazumder, of the University of Michigan, Ann Arbor, received the 2003 Arthur L. Schawlow Award from the Laser Institute of America in recognition of his outstanding contributions in the applications of lasers for science, industry, and education.

David Miller, of The Pennsylvania State University, has received the MBE Innovator Award from the North American Molecular Beam Epitaxy (NAMBE) organization, an award co- sponsored by Veeco Instruments Inc., for inventing arsenic capping and the valved arsenic cracker while employed at the Rockwell Science Center and, later, at Penn State.

Charles Ramiller of IBM has been named by International SEMATECH as director of its Front End Processes (FEP) Division, which provides robust, costeffective FEP manufacturing capability and supports continuous complementary metal oxide semiconductor scaling to and beyond the $45 \mathrm{~nm}$ technology node.

Nancy Ross, professor of mineralogy in the College of Science at Virginia Tech, has been named the college's associate dean for research, graduate studies, and outreach.

J. Michael Rowe, of the National Institute of Standards and Technology Center for Neutron Research (NCNR), is the recipient of the Clifford G. Shull Prize in Neutron Science from the Neutron Scattering Society of America

\section{Kristi Anseth Receives NSF Waterman Award}

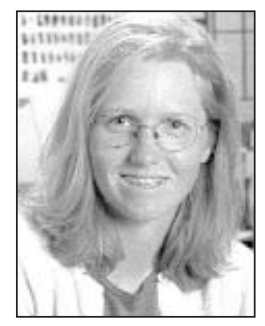

Kristi Anseth, a chemical engineer at the University of Colorado at Boulder, has received the National Science Foundation (NSF) Alan T. Waterman Award, the foundation's most prestigious honor for a young researcher. The award includes a medal and a $\$ 500,000$ grant over a threeyear period to carry out research or advanced study in the field and institution of her choosing. Anseth's award is based on her groundbreaking work in new biomaterials that are engineered to help the body heal itself.

Anseth's group has developed light-activated biomaterials that degrade and interact with cells while promoting tissue regrowth. The hope is that these biodegradable, flexible materials may be available within a decade for medical procedures that will allow the "injection" of new body parts into patients who suffer from debilitating injuries or diseases-without the trauma of major surgery.

Prior awards for Anseth come from many sectors. She earned a Colburn Award from the American Institute for Chemical Engineers as the most outstanding individual in that field under age 36. She received the 2001 Materials Research Society Young Investigator Award. She also received an NSF Faculty Early Career Award (CAREER) to develop a new class of polymers that can be used for orthopedic applications, such as bone repair. Anseth is on the Board of Directors of the Materials Research Society. 


\section{Federico Capasso Highly Honored in 2004}

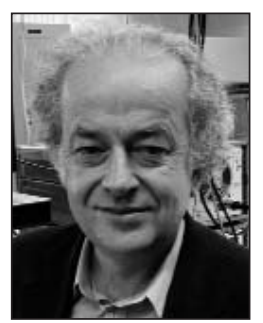

Federico Capasso, the Robert L. Wallace Professor of Applied Physics and Vinton Hayes Senior Research Fellow in Electrical Engineering at Harvard University and a past MRS Medalist, has been awarded the 2004 Arthur L. Schawlow Prize in Laser Science, endowed by the NEC Corporation, from the American Physical Society for his "contributions to the invention and demonstration of the quantum cascade laser and the elucidation of its physics, which bridges quantum electronics, solid-state physics, and materials science." From the Physics Department of the University of Rome "La Sapienza," he has received the 2004 Caterina Tomassoni and Felice Pietro Chisesi Prize for his "contributions to the development of the so-called bandgap engineering, and in particular, for his pioneering work on the quantum laser that represents one of the most important developments in laser physics." From the Institute of Electrical and Electronics Engineers, Capasso has received the 2004 Edison Medal "for a career of highly creative and influential contributions to heterostructure devices and materials."

(NSSA) for "his seminal vision, leadership, and contributions to the field of neutron scattering."

Erwei Shi has been appointed a vice president of the Chinese Academy of Sciences (CAS). He was director of the CAS Shanghai Institute of Ceramics (SIC) from 1998 to 1999. Since 2000, Shi has served as CAS secretary-general.

Richard Smalley, a University Professor, the Gene and Norman Hackerman Professor of Chemistry, and a professor of physics at Rice University, has received the 2003 Small Times Magazine Best of Small Tech Lifetime Achievement Award for his efforts to advance nanotechnology through scientific research, commercial application, and public outreach.

Mark Tuominen and James Watkins will serve as co-directors and Thomas P. Russell as the associate director for the University of Massachusetts's MassNanoTech, a newly established interdisciplinary research center in nanotechnology.

Thomas J. Webster has been selected to receive the Young Researcher Excellence Award from Purdue University's Schools of Engineering. The award recognizes early excellence with clear potential for future preeminence in research by faculty in the Schools of Engineering.

Gerhard Wegner, director at the Max Planck Institute for Polymer Research (MPI-P) in Mainz, Germany, received the 2003 Gold Medal from the Federation of European Materials Societies (FEMS) in recognition of outstanding contributions to the field of materials science; it is the premier award of FEMS.

Christian M. Wetzel, a research pioneer in semiconductor device design and manufacturing, has received a faculty appointment to the Future Chips constellation within the Physics Department at Rensselaer Polytechnic Institute.
The National Academy of Engineering announced the election of 76 new members and 11 foreign associates in February. Among the new members and associates are:

Arup K. Chakraborty (University of California, Berkeley), for the application of theoretical chemistry to practical problems, including immune system recognition, polymer interfaces, sensor technology, and catalysis

Young-Kai Chen (Bell Laboratories, Lucent Technologies), for contributions to the development of high-speed compoundsemiconductor electronics and optoelectronics for telecommunications;

Sunlin Chou (Intel Corp.) for pioneering work on silicon processes, resulting in 35 years of improvements in accordance with Moore's law;

Larry A. Coldren (University of California, Santa Barbara, and Agility Communications Inc., Santa Barbara), for major contributions to diode lasers, especially vertical-cavity and widely tunable distributed Bragg reflector (DBR) lasers;

Stephen C. Cowin (City College of the City University of New York), for contributions to orthopedic biomechanics, the mechanics of granular materials, and the mechanics of anisotropic elasticity;

Paul D. Dapkus (University of Southern
California, Los Angeles), for contributions and leadership in the development of materials and technologies for photonic devices;

Delbert E. Day (University of MissouriRolla), for the development of radiotherapeutic glass microspheres and their transfer to medical applications;

Elizabeth B. Dussan V (SchlumbergerDoll Research, Ridgefield, Conn.), for innovative contributions to the wetting of solids and complex flows in porous media;

Richard Gambino (State University of New York at Stony Brook), for the discovery of magnetic anisotropy, the enabling technology of magneto-optical recording;

Charles O. Holliday Jr. (E.I. DuPont de Nemours \& Co., Wilmington, Del.), for leadership in DuPont's transformation to sustainable growth through biotechnology, high-performance materials, improved safety, and consumer protection;

E. Trifon Laskaris (GE Global Research, Niskayuna, N.Y.), for pioneering contributions to the design and construction of superconducting magnets for magnetic resonance imaging systems;

Chain T. Liu (Oak Ridge National Laboratory), for advancing ordered metallic compounds from the laboratory to practice;

Andrew J. Lovinger (National Science Foundation), for correlating the processing, structure, and properties of important polymeric materials, particularly electronic polymers;

David A. Markle (Ultratech Stepper Inc., San Jose, Calif.), for the invention and development of advanced photolithography systems used to manufacture semiconductor devices;

John H. Perepezko (University of Wisconsin-Madison), for innovations in solidification processing to obtain useful microstructured, nanostructured, and amorphous materials;

Julia M. Phillips (Sandia National Laboratories), for leadership and distinguished research in the epitaxy of dissimilar materials;

Kenneth L. Reifsnider (University of Connecticut, Storrs), for the development of strength-life relationships in composite materials and structures;

Esther S. Takeuchi (Wilson Greatbatch Technologies Inc., Clarence, N.Y.), for the development of silver/vanadium oxide batteries for implantable cardiac defibrillators and lithium/carbon monofluoride cells to power implantable pacemakers;

Daniel C. Tsui (Princeton University), for contributions to the understanding of the quantum physics of two-dimensional electron systems at semiconductor interfaces;

Robin J. Batterham (Rio Tinto Limited, Melbourne, Australia), for modeling of 

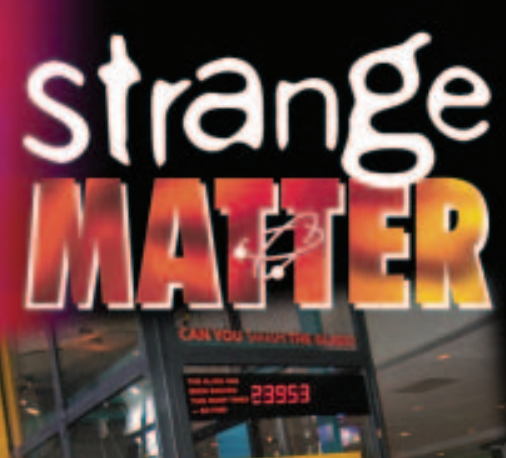

(1)
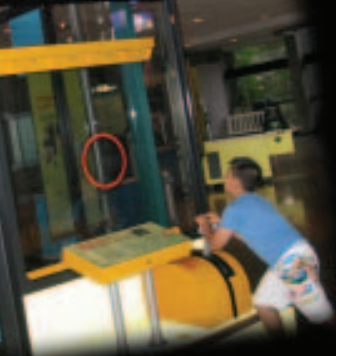

-

\section{mash the 르s:}

Crank up a bowling ball and let it fly you'll find out if heat-tempered glass has the strength to withstand the shock or if the pane of glass will shatter. A counter will allow visitors to keep track of how many times the glass has been hit. Will the glass shatter in 10 minutes, 10 hours, 10 days.

$$
10 \text { months? }
$$

\section{Experience the interactive materials} science exhibit:

Virginia Air \& Space Center Hampton, VA

May 29-September 6, 2004 www.vasc.org

\section{Museum of Discovery and Science} Ft. Lauderdale, FL

June 11-September 6, 2004 www.mods.org

To volunteer for activities with the exhibition, contact

Kaveri Chaturvedi

Community Resources Coordinator kaverisch@msn.com

Strange Matter is presented by the Materials Research Society. This exhibition and its tour are made possible by the generous support of the National Science Foundation, Alcan Inc., Dow, Ford Motor Company Fund, Intel Innovation In

Education, and the 3M Foundation.

\section{MRS}

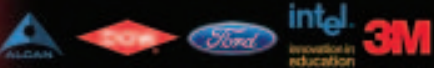

iron ore systems and team leadership in the development of innovative industrial metallurgical processes;

Manuel Elices (Escuela de Ingenieros de Caminos-UPM, Madrid, Spain), for contributions to fracture mechanics of concrete at cryogenic temperatures and stress corrosion cracking of pre-stressed steel, and for inspiring leadership;

Herbert Gleiter (Research Center Karlsruhe, Karlsruhe, Germany), for contributions to the theoretical and practical uses of nanostructured materials;

Ludwik Leibler (CNRS, Ecole Superieure de Physique et Chimie Industrielles, Paris), for fundamental theoretical insights into the structure, self-assembly, and properties of polymer-based formulations;

Herbert A. Mang (Vienna University of Technology), for contributions to computational mechanics of concrete and finite element analysis of reinforced concrete structures;

Choon Fong Shih (National University of Singapore, Singapore), for the development of innovative computational methods in nonlinear fracture mechanics and for international leadership in engineering; and

John R. Willis (University of Cambridge), for contributions to the micromechanics of engineering materials and the establishment of rigorous bounds on the properties of nonlinear composites.

\section{MRS Online}

\section{E-Mail Alerts}

Sign up for any of these FREE services today and let the

Materials Research Society bring materials information to you!

\section{eMatters}

delivers a monthly "snapshot" of what's new in the materials research communityresearch news, important links, professional opportunities, and more

\section{MRS Table of Contents Alert}

delivers advance table-of-contents listings for JMR and MRS Bulletin

\section{Just Published! Book Alert}

provides announcements of newly published proceedings and books from MRS

\section{MRS Meetings Alert}

offers regular updates on upcoming meetings and workshops from MRS - call for papers announcements, abstract submission deadlines, registration dates and discounts, program and speaker updates, etc.

\section{MRS Meeting Scene}

Can't attend an MRS Meeting? This e-mail will keep you abreast of each day's exciting activities and developments.

\section{MRS Public Affairs Alert}

provides occasional calls-to-action and/or summaries of current public-policy issues affecting the materials science and engineering communities

\section{Women in MSEE}

A mailing list for continuing discussion and information exchange on issues affecting women in the materials profession. Women and men are both welcomed to participate.

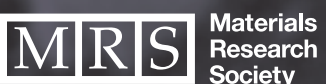

For more information, go to...

www.mrs.org/alerts/ 